\title{
Smokers' faces: who are the smokers?
}

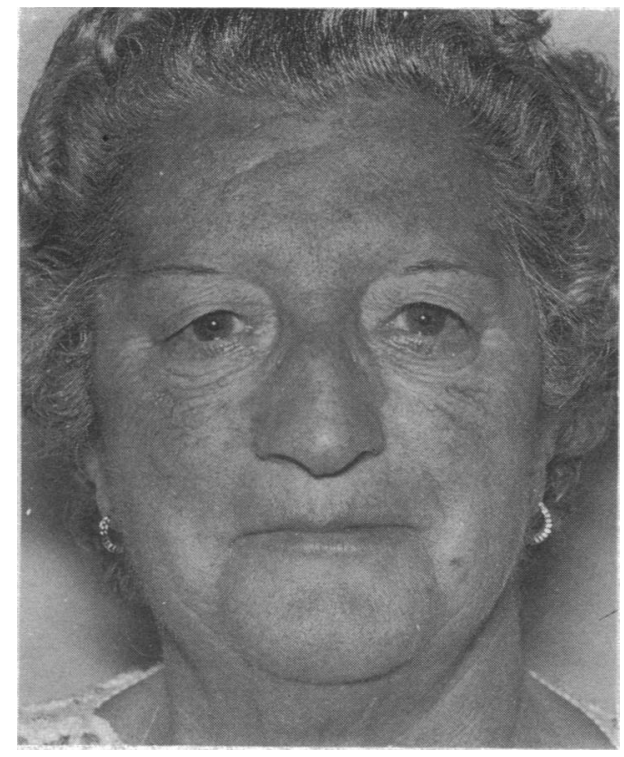

A

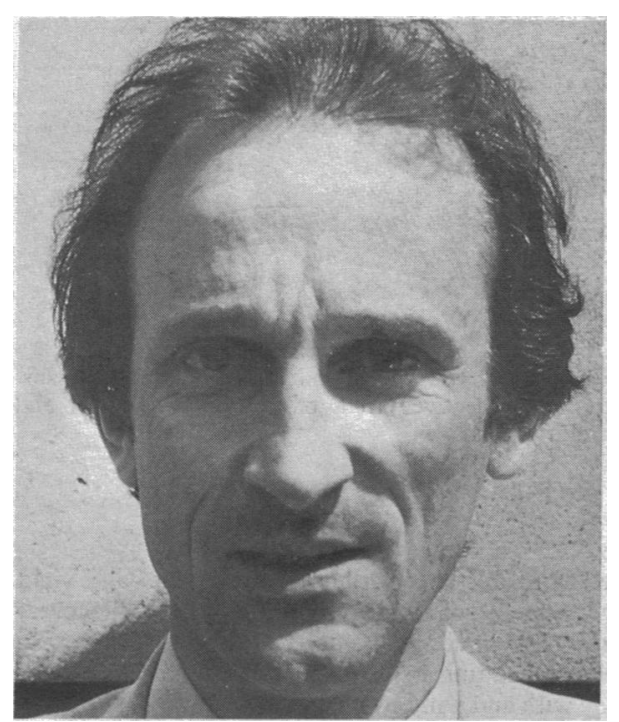

D

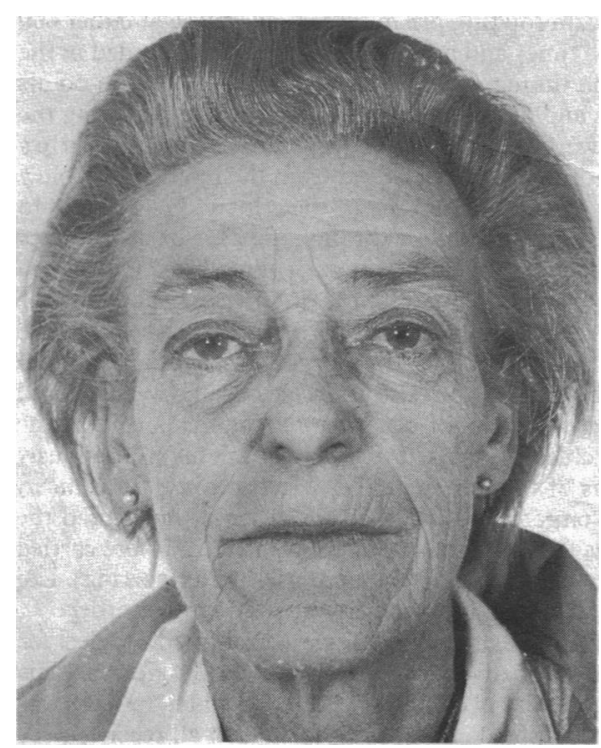

G

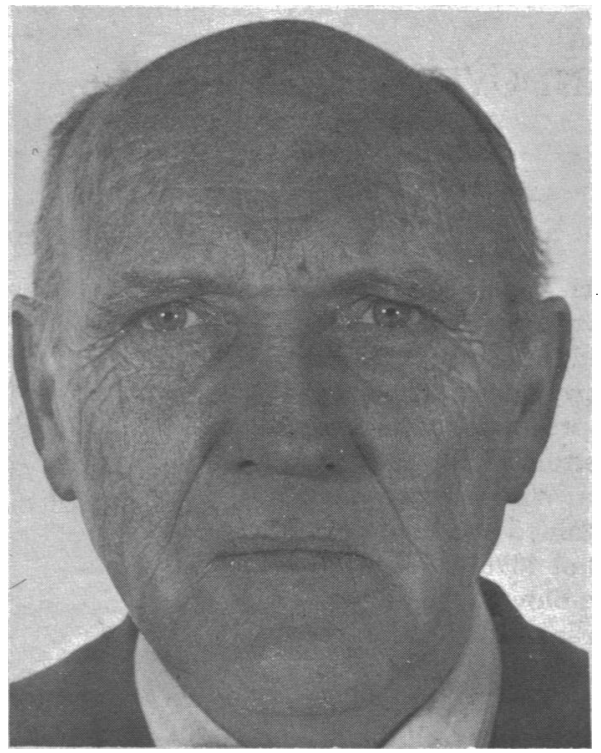

B

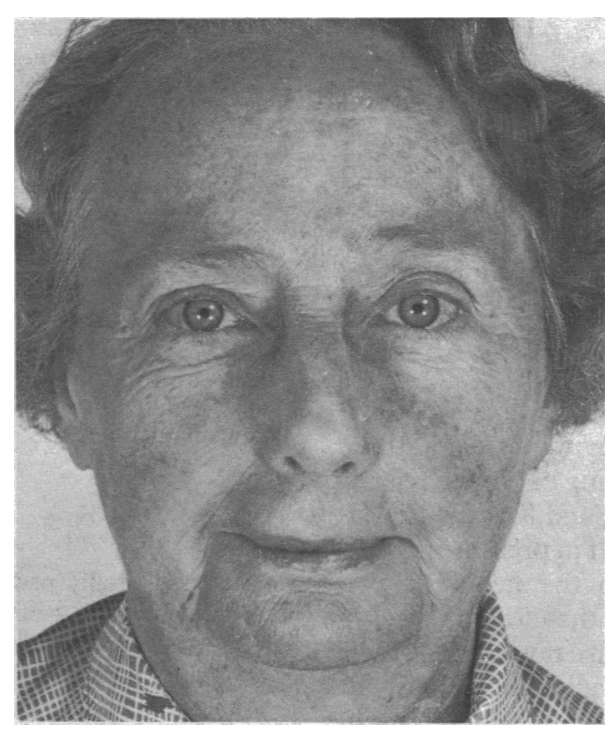

$\mathbf{E}$

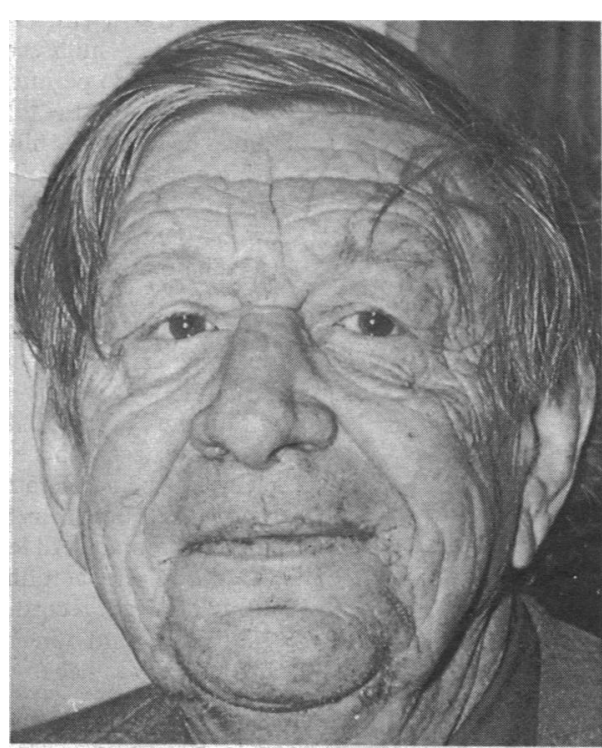

H

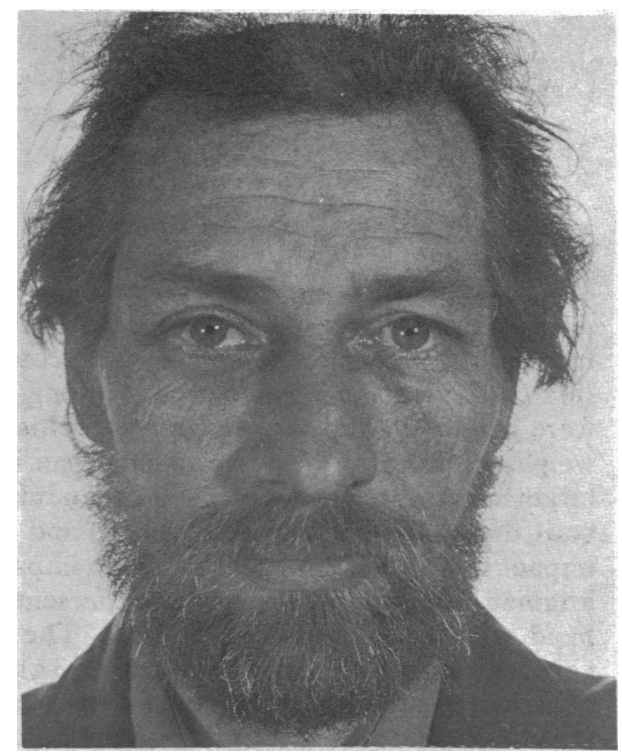

C

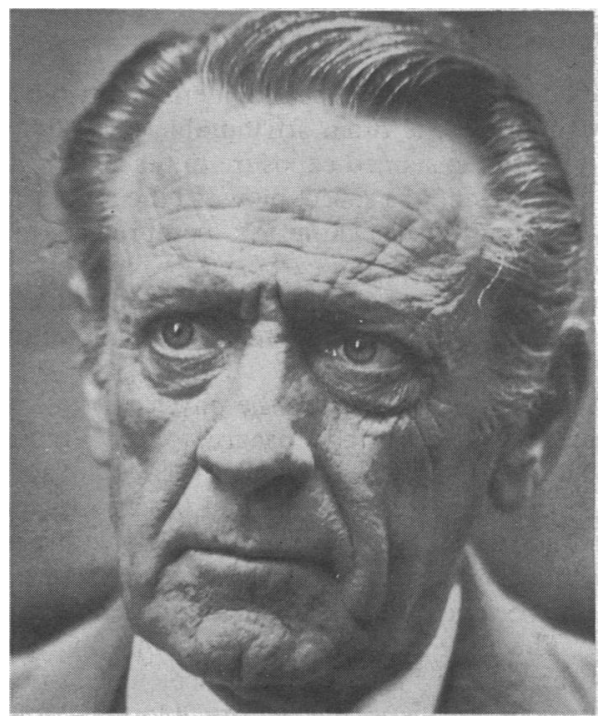

$\mathbf{F}$

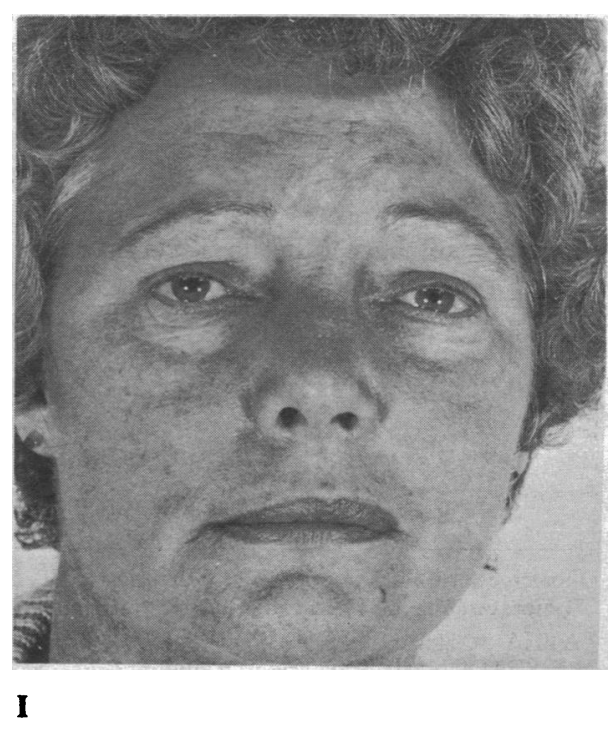

See article on p 1760 and answers on p 1761. 
TABLE I-Smoker's face and state of smoking

\begin{tabular}{|c|c|c|c|c|c|c|}
\hline & \multicolumn{2}{|c|}{$\begin{array}{c}\text { Non- } \\
\text { smokers }\end{array}$} & \multicolumn{2}{|c|}{$\begin{array}{c}\text { Past } \\
\text { smokers }\end{array}$} & \multicolumn{2}{|c|}{$\begin{array}{l}\text { Current } \\
\text { smokers }\end{array}$} \\
\hline & No & $\begin{array}{c}\text { Average } \\
\text { age } \\
\text { (years) }\end{array}$ & No & $\begin{array}{c}\text { Average } \\
\text { age } \\
\text { (years) }\end{array}$ & No & $\begin{array}{c}\text { Average } \\
\text { age } \\
\text { (years) }\end{array}$ \\
\hline $\begin{array}{l}\text { Smoker's face present } \\
\text { Smoker's face absent }\end{array}$ & 38 & $54 \cdot 8$ & $3^{3^{*}}$ & $\begin{array}{l}60 \cdot 0 \\
61 \cdot 1\end{array}$ & $\begin{array}{l}19 \\
22\end{array}$ & $\begin{array}{l}53 \cdot 8 \\
52 \cdot 0\end{array}$ \\
\hline Total & 38 & & 37 & & 41 & \\
\hline
\end{tabular}

*Two women, one man.

TABLE II-Exposure to the sun, social class, and smoker's face in current cigarette smokers and non-smokers

\begin{tabular}{lcc}
\hline & $\begin{array}{c}\text { No (\%) of smokers } \\
\text { with smoker's face }\end{array}$ & $\begin{array}{c}\text { No (\%) of non-smokers } \\
\text { without smoker's face }\end{array}$ \\
\hline $\begin{array}{l}\text { Non-manual class } \\
\text { Manual class }\end{array}$ & $7(47)$ & $27(100)$ \\
Exposed to sun & $12(46)$ & $11(100)$ \\
Not exposed to sun & $7(52)$ & $16(100)^{\star}$ \\
\hline
\end{tabular}

*Information not available on two patients in these groups.

face related to a recent change in weight or to the number of cigarettes smoked in the patient's lifetime, roughly estimated as the number of cigarettes currently smoked a day times the number of years of smoking. Thus among the 19 current smokers with smoker's face 13 had steady weight and two were heavier and four lighter than a year before. Similarly, although the estimated lifetime consumption of cigarettes among the smokers with smoker's face (mean 669 (SD 376) cigarette years) was slightly greater than that among those without smoker's face (mean 542 (363) cigarette years), the difference was not significant.

The diagnoses among the patients were varied as might be expected in a

Smokers' faces: answers

\begin{tabular}{l|} 
Non-smoker \\
67 year old woman \\
\\
A
\end{tabular}
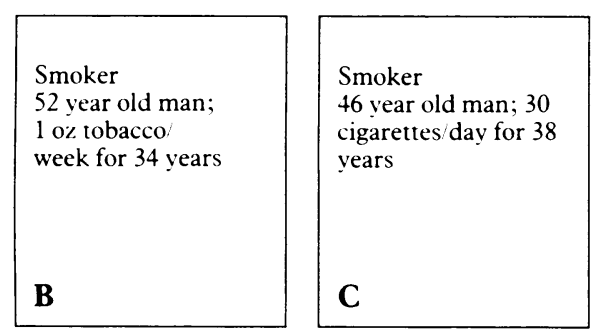

\begin{tabular}{l|}
\hline Non-smoker \\
David Simpson, \\
director of Action \\
on Smoking and \\
Health \\
\\
D \\
\hline
\end{tabular}
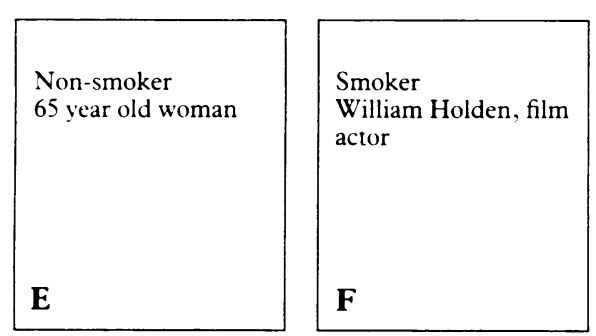

\begin{tabular}{|l|} 
Smoker \\
62 year old woman; 20 \\
cigarettes/day for 40 \\
years
\end{tabular}

general medical outpatient clinic. No association was evident between smoker's face and diseases either related (eight cases) or unrelated (14 cases) to smoking.

\section{Discussion}

This survey confirms the findings of Ippen and Ippen ${ }^{12}$ and Daniell $^{2}$ that cigarette smoking causes readily recognisable wrinkling and other changes to the faces of many people. Daniell's large study, however, was mainly concerned with grading the degree of facial wrinkling for the whole of his study population and relating the various grades to the number of cigarettes smoked a day. By contrast this study was concerned with identifying only the subgroup of people within a population who fulfil the defined criteria of a clinical sign allowing them to be picked out as cigarette smokers. Perhaps the reasons that these changes have not been more generally associated with smoking is that smoker's face is fairly common and has been accepted as part of the normal appearance of the face.

One possible criticism of this work is that assessing faces in this way is necessarily subjective. Similar subjective limitations, however, are accepted in the assessment of physical signs such as hypothyroid facies, depression as an expression of the face, cyanosis, anaemia, and clubbing of the finger nails. Moreover, just as Daniell found that children can learn to recognise smoker's face, I found that nurses and medical students quickly learn to recognise the sign, which confirms that it really exists.

The results reported here were obtained in patients attending a general medical outpatient clinic in the south east of England. Two important qualifications result from this. The first is that such a group of people is highly selected, and that the prevalence of smoker's face generally may be different from that reported here. Thus, although smoker's face was found in subjects from all social classes, the numbers within each group were too small to estimate its prevalence in smokers from each class. Similarly, because only one person in the survey was not white it was not possible to comment on the observation of Allen et al that regardless of whether or not they smoke wrinkling does not occur in black Americans. ${ }^{13}$ The second qualification is that this survey was conducted in a cool, temperate climate where the power of the sun is fairly weak. In other parts of the world where race, exposure to the sun, and nutrition are different, the criteria for smoker's face may be rather different as it is generally agreed that sunlight damages the skin of white people. ${ }^{15}$ Thus Daniell, reporting from sunny California, found that smoking and exposure to the sun each separately caused wrinkling of the face and that together they had a considerably greater effect. ${ }^{2}$

Two possible explanations arise for the observation that so few past smokers had smoker's face: either they had had smoker's face and it had disappeared when they stopped smoking or they were smokers who had never had smoker's face. A longitudinal survey of people who stop smoking would be required to decide this point. Likewise, a further study would be necessary to investigate my impression that obesity tends to obscure smoker's face, presumably by stretching and filling out lines on the face and also filling out the cheeks. Conceivably it was because of weight gain that so few past smokers had smoker's face.

In this survey only four people admitted to having 25 or more alcoholic drinks a week, and only one of these was a current smoker with smoker's face. His face was lined rather than plethoric. It therefore seems unlikely that smoker's face was confused with the plethora of alcoholism.

How does smoking bring about the observed changes? In some ways smoker's face resembles an aging process, but on the other hand, the similarity in the average ages of the current smokers with and without smoker's face and the fact that so many of the people with smoker's face were fairly young indicate that smoker's face is not simply a symptom of age. The changes in the colour and quality of the skin suggest a toxic process. Recently Klemp et al and Reus et al showed that smoking reduces the circulation to the skin in man $^{16}$ and nude mice ${ }^{17}$ respectively. Perhaps biochemical and histological investigations would elucidate other changes. Likewise the contribution of any genetic factor would need further investigation. 